\title{
Transmission frequency of COVID-19 through pre-symptomatic and asymptomatic patients in AJK: A report of 201 cases
}

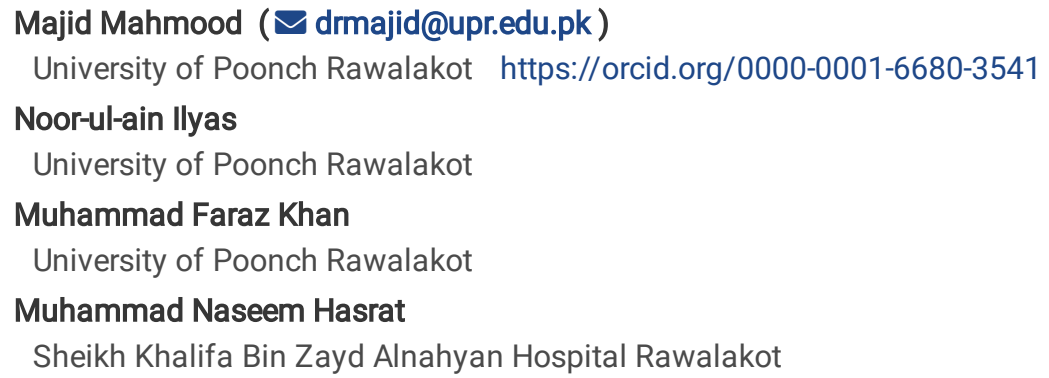

\section{Research}

Keywords: COVID-19, COVID-19 transmission, COVID-19 patients, pre-symptomatic, asymptomatic, AJK, Pakistan

Posted Date: February 19th, 2021

DOI: https://doi.org/10.21203/rs.3.rs-152710/v3

License: (c) (i) This work is licensed under a Creative Commons Attribution 4.0 International License. Read Full License 


\section{Abstract}

Background: Corona virus disease 2019 (COVID-19) caused by severe acute respiratory syndrome coronavirus 2, declared as "once-in-acentury" pandemic, has affected about entire human population. Till now, the most promising control strategy is to block the transmission which will never be effective without completely knowing the transmission patterns.

Methods: This was a retrospective case to case study aiming to estimate and calculate the transmission rate of COVID-19 through presymptomatic and asymptomatic patients. Contact history of included positive cases during the period of 24 hours before appearance of symptoms and infection confirmation for symptomatic and asymptomatic cases respectively was traced for disease transmission.

Results: Overall, a total of 201 cases had contacted with 7168 people in last 24 hours with an average of 35.66 contacts per patient ranging from a minimum of 4 to maximum of 87 contacts (Meetings). Out of 7168 meeting persons, the infection was traced in 64 (0.89\%) persons. For 155 symptomatic patients, a total of 5611 contacting persons were traced before appearance of symptoms (pre-symptomatic) in last 24 hours with an average of 36.20 meetings per patient. The infection was transmitted in $63(1.12 \%)$ people and remaining 5548 (98.88\%) were remained uninfected. Out of the 63 transmissions, 62 (98.4\%) were traced within last 6 hours before the onset of symptoms while only 1 was traced from 6-12 hours before symptoms. A total of 1557 persons were traced having meeting/contacts with asymptomatic cases in last 24 hours before their infection confirmation. Out of these 1557 persons, only 1 was found to be infected and the infection rate was calculated to be $0.06 \%$.

Conclusion: The study concludes that the risk of pre-symptomatic transmission of infection is low $(1.12 \%)$ and it becomes very rare in contacts made longer than 6 hours before onset of symptoms. The infection transmission is traced as long as about 9 hours before the appearance of clear symptoms in the patients but the incidence was as low as about $0.02 \%$ of the total contacts in that period. Transmission frequency by asymptomatic patients is also rare $(0.06 \%)$ in the studied population.

\section{Background}

Corona virus disease caused by severe acute respiratory syndrome coronavirus 2 (SARS-CoV-2), declared as "once-in-a-century" pandemic, has affected entire human population [1]. To date, more than 79.67 million cases have been confirmed worldwide and the cumulative deaths have exceeded 1.76 Million [2]. The most devastating aspect of corona virus is its exponential rate of transmission [3]. It is now known that a significant fraction of infected patients do not show any symptoms of disease and remains asymptomatic. Moreover, the symptomatic patients also show symptoms after a period of varied length during which, they can be called as pre-symptomatic [4-11]. Asymptomatic and pre-symptomatic patients, if not known for a confirmed contact with some disease source, are often not noticed and people do not hesitate to meet them without sufficient protective measures. The question about the transmissibility of pre-symptomatic and asymptomatic patients has not been addressed comprehensively although a good number of reports are available online in support of asymptomatic and pre-symptomatic transmission of SARS-CoV2 [12-22]. However, most of the previous studies reporting asymptomatic and pre symptomatic transmission are based on single or very few cases with many limitations [22]. Moreover, it is still to be calculated that up to how much extent a pre-symptomatic patient or an asymptomatic carrier can transmit the virus. Exact rates of transmission from patients without symptoms are still not known as it is difficult to calculate. The proportion of asymptomatic carriers in any population cannot be exactly estimated as prevalence and transmission rate of asymptomatic patients varies from rare to very high in different studies with different methodologies [23-24].

Despite all efforts to contain, the contagion is still finding new hosts and hence transmission is unstoppable. There is a consensus in global health leaders that vaccines alone will not be sufficient to take this virus under control as challenges of mass production and fair distribution are yet to be addressed [25]. Meanwhile, recent news of more transmissible mutants from certain parts of the world reiterate the need of more insight about spreading of infection [26]. Till now, the most promising control strategy is to block the transmission which will never be effective without completely knowing the transmission patterns and sources of infection. Real case-to-case studies on pre-symptomatic and asymptomatic patients in different populations of the world are merited to assess, estimate and calculate possible transmission of COVID19. The present study was designed and conducted to assess and estimate the rate of transmission through asymptomatic and presymptomatic subjects from a selected region of Azad Jammu and Kashmir, Pakistan.

\section{Methods}

\section{Study design and study area}

The present study was a combination of 201 case studies, retrospectively conducted by contact trace strategy in which a total of 155 symptomatic and 46 asymptomatic COVID-19 patients belonging to different areas of district Poonch and district Sudhnuti, Azad Jammu 
and Kashmir (AJK) were included. The study was conducted in the period of September to November 2020. The last date for data calculation was set to be October 10, 2020.

\section{Patients' selection and records acquisition}

The patients were traced from three hospitals of the area which are: 1- Sheikh Khalifa Bin Zayd Al-Nahyan Hospital, Rawalakot; 2- District headquarter hospital Palandari, and Tehsil headquarter hospital Hajira. Along with the hospitals, the patients' records were also traced through the offices of district health officers and surveillance officers of districts Poonch and District Sudhnuti, AJK. The obtained patients' record included patients' name, gender, age, home address, telephone number, profession, quarantine or admission duration, symptoms, PCR test report, and the outcome after admission or quarantine. After retrieving the records and assessing the data, 386 patients were initially selected for meetings and enrolment in the study.

\section{Final selection of patients and inclusion in study}

All the patients who met the investigator were finally included in the study while patients unable to meet were not included. Out of the selected 386 patients, 375 were contacted by telephone calls or other means to obtain their consent for meeting and interview while 11 of them remained out of contact by all means. Out of 375 contacted patients, 313 were found to be present in study area while 62 had out of the area due to different reasons and were not accessible. Out of 313 accessible patients, 22 refused to meet and participate in the study while 291 agreed for meeting and to participate in study (Figure 1).

\section{Meetings with patients and interviews}

After the final selection of the participating patients, the meetings were arranged for interviews and confirmation of records. Out of the 291 patients agreed for meeting and participation in the study, successful meetings and interviews could only be conducted with 201 patients and not with remaining 90 patients due to different reasons. These 201 patients included 155 symptomatic and 46 asymptomatic patients. The meetings were conducted on different places according to ease of both patients and the investigators. The meeting places included the department of Zoology, University of Poonch Rawalakot, three hospitals of the study area and patients' homes. A pre-developed tabulated questionnaire and a data sheet were used to record the required information and data in interview. The collected information included patients name, age, gender, area of residence, profession, place of job or study, date of appearance of symptoms, date of infection confirmation by PCR, possible date of infection, possible source of infection, history of hospital admission or quarantine, persons meeting in last 24 hours before the appearance of symptoms in case of symptomatic patients and before the confirmation by test in case of asymptomatic patients, persons meeting in different retrospective periods from 0 to 24 hours before the appearance of symptoms or confirmation of infection, the ways of contacts with meeting persons and, the detail of meeting persons to patient (Figure 1).

\section{Data of meeting persons to trace the transmission}

The detailed information of close relatives of patients in meeting persons was obtained in the meeting with patient while the remaining meeting persons were contacted and traced with the help of participating patients. The data of total 7168 meeting persons was collected. Majority of the meeting persons was found to be family members, close relatives, friends, working colleagues, or neighbors of the patients. The collected data of meeting persons included their quarantine history, PCR test, appearance of symptoms, and their current status to confirm the transmission. The data of a fraction of meeting persons was collected during the meeting with original participating patient while the remaining was obtained by meetings and telephone calls on the base of availability and accessibility (Figure 1).

\section{Informed consent and ethics approval}

Only the patients agreed to participate were included in the study. Each patient was informed about the use of their data and all of them signed a written informed consent. The study was approved by the institutional ethics committee of University of Poonch Rawalakot.

\section{Data arrangement and analysis}

All the data was entered in MS excel data sheets. Means, median, standard deviation, minimum value, maximum value, and percentages were calculated for different parameters and infection transmission rate.

\section{Results}

The current study traced the transmission of COVID-19 by 201 cases including 126 male (62.7\%) and 75 female (37.3\%) patients. For each of the 201 patients a separate case study was conducted which included 155 pre-symptomatic and 46 asymptomatic patients. A total of 7168 individuals who met with these 201 pre-symptomatic or asymptomatic patients during a time period of 24 hours before the appearance 
of symptoms or confirmation of infection (mean meetings per patient $=35.66$ ) were traced in the study for confirmation of transmission. Out of 7168 contacts 64 individuals were found to be infected with COVID-19 with a transmission rate of $0.89 \%$ (Table 1). No case of infection was observed in remaining 7104 contacting persons even after a mean duration of $84 \pm 43$ days with minimum of 23 days from the date of infection confirmation in patients. Out of the total 64 infected individuals, 63 were recorded to have contraction from pre-symptomatic patients while only 1 patient was traced to acquire infection from asymptomatic patients (Figure 1). The net rate of pre-symptomatic and asymptomatic transmissions were found to be $1.12 \%$ and $0.06 \%$ respectively (Table 1 ). Transmission of infection was found to be very low by pre-symptomatic patients and almost singular by asymptomatic patients.

\section{Pre-Symptomatic Transmission}

Out of the total 201 cases, 155 were symptomatic who had 5611 contact events during last 24 hours before the appearance of symptoms. Mean persons meeting a pre-symptomatic patient was calculated to be 36.20 . Out of these 5611 people, 5548 (98.88\%) remained uninfected even after random testing and over a mean duration of $85.32 \pm 43.5$ days ranging from minimum of 24 days to maximum of 210 days, while 63 of these individuals $(1.12 \%)$ were tested positive. Overall percentage of transmission by pre-symptomatic patients $(1.12 \%)$ was observed to be very low (Table 1; Table 2). Time line of contact event was as follows: Out of the total 5611 persons contacting the symptomatic patients before the symptoms, 1544 persons met the patients in the period of 6 hours to 0 hour before appearance of symptoms, 1410 meetings were traced in period of 12 to 6 hours, 1285 in period of 18 to 12 hours and 1372 meeting were traced in period of 24 to 18 hours before appearance of symptoms in patients. Sixty two (62) of the 63 transmissions (98.4\%) were traced in the period of 0-6 hours before appearance of symptoms while 1 transmission (1.6\%) was traced in the meetings during 6 to 12 hours before appearance of symptoms (Table 2). So, majority of the transmission events (98.4\%) occurred in the meetings just before the appearance of symptoms while very rare transmission occurred in the meetings before 6 hours of appearance of symptoms or more (Table 2). The transmission rate was calculated to be about $4 \%$ during $0-6$ hours before appearance of symptoms while it was only $0.02 \%$ in contacts before 6 hours to 24 hours of the symptoms (Table 2). The risk of getting infection from a pre-symptomatic patient before 6 hours or more of from onset of symptoms is very rare.

\section{Asymptomatic Transmission}

A total of 46 out of 201 positive cases never developed any disease symptom in the study even after a mean duration of $82.74 \pm 42.5$ days ranging from minimum 23 days to maximum 180 days after tested positive. These patients were designated as asymptomatic and a total of 1557 persons were traced who had meetings with these 46 patients before they were tested positive. Out of these 1557 individuals meeting the asymptomatic patients during a mean time period of 24 hour before tested positive, only 1 person was tested positive. Interestingly, this individual who had 2 days of meeting developed mild symptoms of COVID-19 just 3 days after the meeting. This person was the brother of an asymptomatic patient and met the patient approximately about 8 hours before the appearance of symptoms in the patient. All of other traced persons (1556 out of 1557) remained asymptomatic throughout the study and were never tested positive. The transmission rate by asymptomatic patients was found to be $0.06 \%$ (Table 2).

\section{Some selected case reports}

Separate case study was conducted for each of the 155 pre-symptomatic and 46 asymptomatic positive patients. Here we discuss 4 presymptomatic cases and 4 asymptomatic cases as example selected out of total 201 cases (Table 3).

Case 1: Symptomatic, transmission not traced: A 45 years old male working as a labor in a floor mill returned to work from his home town after Eid-ul-Fitr holidays on May 29 and met 42 co-workers. He has been living there for about 30 hours in shared living area mess and lavatory with all of 42 co-workers. After about 27 hours, he expressed symptoms which a roommate of him identified as of COVID-19 and informed the hospital officials. The patient was carried and admitted to the hospital where he was tested positive and stayed for 19 days before complete recovery. Meanwhile, all 42 contact persons were kept in quarantined for 14 days and a random testing was carried out in which 25 of them were tested on day 7 . All the 25 were found negative on day seven and none of those 42 individuals showed any symptom after day 14 . Even after 150 days of their meeting with the patient, none of the persons was found infected. The transmission rate was $0 \%$ in this case (Table 3 ).

Case 2: Symptomatic, transmission not traced: A 21 year old male student from a village near Rawalakot carried infection from some patient in Rawalpindi and got symptoms appeared on the morning of August 1, 2020, just a day after Eid-ul-Adha. In previous 24 hours, 32 persons were traced to meet him without any precautionary measures including his family members and relatives. Early in the morning of the day next to the Eid-ul-Adha, he met with his father, mother, sister, father's sister and 3 male cousins just before the appearance of fever. After the appearance of fever, he quarantined himself. He was brought to the hospital next day where he was found positive for COVID-19 on PCR test and got hospitalized. . All the 32 individuals having close contact with him were kept in isolation immediately and 21 of them were selected

Page $4 / 11$ 
randomly for test after 8 days. All tested persons including the patients family members were found negative and non of the all 32 showed any symptom after 14 days of contact and even after 70 days (on date of data collection). The patient recovered and was discharged from hospital after 12 days. Transmission rate in this case was $0 \%$ in this case (Table 3 ).

Case 3: Symptomatic, transmission traced: The 3rd selected case was a 66 years old male who showed symptoms on July 8,2020 and found positive on PCR test. Just before the appearance of symptoms, on the same day, he visited a total of his 56 relatives and family members residing in Rawalakot and had intimate contact history. At about 9 pm, he felt fever and chest pain which became severe until the next morning and he was brought to the hospital where he was tested positive for COVID-19 and got admitted. After 22 days of hospital stay, he recovered and was discharged from the hospital. All the 56 meeting persons were quarantined themselves at home and 28 of them went for a PCR test. One of the meeting persons developed symptoms after 9 days and also tested positive while 27 of the tested persons were negative. Except for one positive and symptomatic person, no meeting person showed symptoms or tested positive. The transmission frequency was calculated to be $1.8 \%$ in this case (Table 3 ).

Case 4: Symptomatic, transmission traced: The 4th selected case was a female of 47 years old in Hajira, district Poonch AJK. She probably got the infection during a hospital visit. She was at home on June 15 and 16, where she met many relatives and family members before and during the appearance of symptoms on June 16, out of which 27 were traced. The patient was tested positive and recovered after 16 days of hospitalization. All the 27 contacted persons isolated themselves and 11 of the close relatives were tested for COVID-19. Among the close relatives remaining with patient even at the time of appearance of symptoms, two (2) daughters and husband of the patient were tested positive. However, both of the daughters never developed symptoms while husband become symptomatic after only 2 days of the patient. Remaining 24 persons did not develop any symptom after day 14 and even after 84 days of contact. The rate of transmission in this case was calculated to be $11.1 \%$ (Table 3 ).

Case 5: Asymptomatic, transmission not traced: A 29 year old male was found positive when tested after having a meeting with COVID-19 patient and immediately kept in quarantine center for 14 days. Fifty four (54) contacts were traced on the day he got tested for COVID-19. who all of them later isolated themselves at their homes. After 14 days, neither the positive tested person, nor any of the 54 meeting persons had any symptom. For more confirmation, 13 of the meeting persons were randomly tested but all of them were found negative in PCR test. The positive case turned to be negative in his test after the end of quarantine period on day 15 . This case was designated as an asymptomatic patient and no infection transmission was traced by him even after 140 days (Table 3).

Case 6: Asymptomatic, transmission not traced: In this case, a 27 years old female was tested because she was living with her husband who was symptomatic and was tested positive. The female did not have any symptom but was found positive for COVID-19. She and 37 of her relatives who have met her recently before and during test were quarantined at their homes for 14 days where they remained asymptomatic. Moreover, 13 of the persons who were in close contact to the case were tested after a week but they all were negative. All the 37 contacting persons along with the case never developed any of the COVID-19 symptoms even after 130 days. The transmission frequency in this case was $0 \%$ (Table 3$)$.

Case 7: Asymptomatic, transmission not traced: A 50 year old school teacher was found positive during random testing on September 12, 2020. He was kept in quarantine at home immediately and 26 persons meeting him without full precautionary measures before the test were traced and restricted to their home in isolation. After a week, 8 of the family members and relatives who met him with close contact were tested. All the tested persons were negative and none of the 26 meeting persons showed any symptom after day 14 and even after day 28 (Date of data collection). The transmission frequency in this case was found to be $0 \%$ (Table 3 ).

Case 8: Asymptomatic, transmission traced: This was the only asymptomatic case through which a probable transmission was traced. The patient was a 39 years old businessman who was tested positive on July 14, 2020. He was quarantined for 14 days during which he did not showed any symptoms and again tested after quarantine period in which he was negative. Before his test, he met 23 persons including 6 of his family members, who quarantined themselves on their homes after the test. All 6 of the patient's family members and 3 close relatives were selected for test after 5 days in which his 34 years old brother was tested positive but remained asymptomatic throughout the quarantine period. None of the 23 meeting persons showed any symptom even after 88 days of their meeting. The transmission rate was found to be $4.3 \%$ in this case (Table 3 ).

\section{Discussion}

The current study was aimed to trace and estimate the rate of COVID-19 transmission by asymptomatic and pre-symptomatic patients in AJK, Pakistan. As many reports suggested, COVID-19 is transmissible through asymptomatic carriers [13-18,21] and symptomatic patients before their symptoms appear [4, 19-20]. These threatening facts pose a serious challenge to the global public health in mitigation of this pandemic [17]. So far, the only obvious effective practice is to control the transmission. If the virus is being transmitted by asymptomatic

Page 5/11 
and pre-symptomatic cases, it will literally never be possible to completely block the transmission of COVID-19. Moreover, the virus is also suspected to be transmitted by air and environment to some extent [27]. However, the proportion of asymptomatic patients and the transmission rate may not be as higher as it has been thought, otherwise the disease would have infected a huge proportion of the population. In case of AJK majority of the local population in current study area do not observe complete precautionary protocols while meeting to obviously healthy individuals who may be asymptomatic carriers or pre-symptomatic patients. Following precautionary protocols in letter and spirit is practically not expected in this region which has a huge population, high poverty ratio, overcrowded markets, overburdened public transport and big sized families.. Moreover, the population of Pakistan, especially that of hilly areas of Azad Jammu and Kashmir (Study area) is not very serious in their behavior towards the COVID-19.

Herein we found very low transmission (1.12\%) from pre-symptomatic patients and singular transmission (0.06\%) from asymptomatic carriers. The current study was different traced all confirmed contacts (meetings) of the pre-symptomatic patients before symptoms ( $\mathrm{n}=155$ ) and asymptomatic patients $(n=46)$ before their infection confirmation by PCR. The approach used in this study was directed from patient to contacting persons which involved 155 symptomatic patients, 46 asymptomatic patients and7168 healthy contacting persons. A total of 5611 persons were traced having confirm contacts with symptomatic patients prior to the appearance of symptoms while 1557 persons were traced having contacts with asymptomatic patients prior to their confirmation.

Only 63 out of 5611 persons contacting pre-symptomatic patients were confirmed to have the infection (transmission rate $=1.12 \%$ ). The individuals contacting the patients in pre-symptomatic duration were divided in four groups on the base of time duration before the appearance of symptoms and it was found that out of 63 confirmed transmissions, $62(98.4 \%)$ transmissions occurred in the contacts during the period of 0-6 hours before appearance of symptoms. The infection rate in this period was about $4 \%$ of the total contacts in the duration. Only 1 out of 63 transmissions was traced in the contacts made in more than 6 hours before the appearance of symptoms and the transmission rate was $0.02 \%$ which is very rare. This finding leads to a hypothesis that the pre-symptomatic patients transmit more infections near to the time of appearance of symptoms and the risk of infection transmission increases as the time of symptoms appearance come closer. However, the meetings in the closest time of appearance of symptoms are always suspected as mild symptoms may be present in that period and the exact time of appearance of symptoms may not be accurately remembered and determined. So the actual frequency of pre-symptomatic transmission may be a little lesser than the observed one (1.12\%) as some persons getting infections may have contacts with patient at the time of appearance of symptom. So, the period was started from 0 hour instead of 1 hour before the appearance of symptoms.

On the other hand, all the contacts traced in the period of 0-6 hours before symptoms are not confirmed to catch an infection. Many of them might have one or other precautionary measure while meeting and it is possible that the $4 \%$ who caught infection have had a stronger exposure to of infection. Moreover, majority of the people traced to have infection from the patient were close relatives who might have more intimate contacts with patients even after appearance of initial symptoms. So, two conclusions can be drawn on the base of this study which are: 1 - The actual transmission rate by pre-symptomatic patients is less than $4 \%$ in meetings with and without precautionary measures in the duration of 0-6 hours before symptoms; 2- The risk of infection increases in time period closer to the appearance of symptom in patients.

It is, however, traced that the patient starts shedding the virus at least 6 hours before becoming symptomatic and before but the rate of transmission is very low before 6 hours of symptoms (0.02\%). Transmission by patients before appearance of symptoms was reported previously in many studies [4,14-15,22], but how longer before the appearance of symptoms and with what frequency a patient can transmit the virus was not calculated. This is the first attempt to have some insights in pre-symptomatic transmission frequency with relation to time before the symptoms. More studies with sophisticated analytics and robust testing will confirm the transmission dynamics through presymptomatic patients in relation to time.

Among the 1557 contacts of 46 asymptomatic patients traced before their infection confirmation, only 1 was found to be infected. The transmission rate by asymptomatic patients was found very rare $(0.06 \%)$. This singular case was traced to have close contact with one of the asymptomatic patients about 9 hours before the confirmation of the patient by PCR test. However, this patient did not develop any of the symptoms and remained asymptomatic (Case 8). The person was real brother of the asymptomatic patient and tested positive after 5 days of his meeting with original patient. No probable source of infection other than his brother was traced. So it was concluded that he got infection from his asymptomatic brother. Strangely, the other family members meeting at same time or after his meeting were not tested positive.

A lot of previous studies reported transmission of COVID-19 by asymptomatic patients [5-6,12-13,16-22]. The present study, however, failed to trace and confirm the transmission of COVID-19 by asymptomatic patients except in only 1 out of 1557 contacts which is very rare frequency. So, the actual transmission risk cannot be determined still and it needs further investigations. 


\section{Conclusions}

The study concludes that the transmission of COVID-19 by pre-symptomatic patients in AJK, Pakistan is only about $1.12 \%$ of the contacts before symptoms. The patients can start transmitting the virus about 6 hours before the appearance of symptoms. Transmission risk is higher in times closer to the time of symptom appearance while the risk is very low in times before more than 6 hours of appearance of symptoms. The transmission frequency of COVID-19 by asymptomatic carriers is very rare $(0.06 \%)$.

\section{Abbreviations}

COVID-19: Corona Virus Disease 2019; AJK: Azad Jammu and Kashmir; DHQ: District Head Quarters; SARS-CoV-2: Severe Acute Respiratory Syndrome Coronavirus 2; PCR: Polymerase Chain Reaction; MS: Microsoft; Min-Max: Minimum-Maximum; UPR: University of Poonch Rawalakot

\section{Declarations}

\section{Ethics approval and consent to participate}

The study was approved by "Human and animals ethics committee", university of Poonch Rawalakot, AJK, Pakistan. All study participants were informed about study and they signed a written informed consent form before participation in the study.

\section{Consent for publication}

Not Applicable

\section{Availability of data and materials}

All the data of this study is available on request from corresponding author.

\section{Competing interests}

No competing interests exists among authors.

\section{Funding}

No funding was available for this research

\section{Authors' contributions}

MM conceptualized and designed the study, analyzed the data and wrote the initial draft. $\mathrm{NI}$ and MNH conducted interviews, collected and organized the data. MFK wrote the manuscript parts and critically reviewed the manuscript. All authors have read and approved the final version of manuscript.

\section{Acknowledgements}

The authors are thankful to Miss Sana Khurshid and Miss Saneeza Nadeem, department of Zoology, UPR, for their cooperation in data acquisition and arrangement. The authors are also thankful to Mr. Zia-ur Rehman, department of Zoology, UPR, who helped in arrangement of data and making the figure.

\section{References}

1. Gates B. Responding to COVID- 19- a once - in- a - century pandemic. N Eng J Med. 2020; 382:1677-1679. Doi. 10.1056 / NEJMp2003762.

2. WHO, 2020. https://covid19.who.int/. Accessed on December 28, 2020.

3. Kang S, Jung SI. Age related morbidity and mortality among patients with COVID-19. Infect Chemother. 52(2). 154-164. 10.3947/ic.2020,52.154.

4. Qian G., Yang N., Ma A.H.Y., Wang L., Li G., Chen X. and Chen X. COVID-19 Transmission Within a Family Cluster by Presymptomatic Carriers in CHINA. Clin Infect Dis. 2020; 71(15):861-862. 
5. Wang Y, Liu Y, Liu L, Wang X, Luo N, Ling L. Clinical outcome of 55 asymptomatic cases at the time of hospital admission infected with SARS-coronavirus-2 in Shenzhen, China. J Infect Dis. 2020; 17. https://doi.org/10.1093/infdis/jiaa119

6. Chan JF, Yuan S, Kok KH, To KK, Chu H, Yang J, et al. A familial cluster of pneumonia associated with the 2019 novel coronavirus indicating person-to-person transmission: a study of a family cluster. Lancet. 2020;395:514-23. https://doi.org/10.1016/S01406736(20)30154-9

7. Chang L, Zhao L, Gong H, Wang L, Wang L. Severe acute respiratory syndrome coronavirus 2 RNA detected in blood donations. Emerg Infect Dis. 2020. https://doi.org/10.3201/eid2607.200839

8. Dong Y, Mo X, Hu Y, Qi X, Jiang F, Jiang Z, et al. Epidemiological characteristics of 2143 pediatric patients with 2019 coronavirus disease in China. Pediatrics. 2020; https://doi.org/10.1542/peds.2020-0702

9. Mizumoto K, Kagaya K, Zarebski A, Chowell G. Estimating the asymptomatic proportion of coronavirus disease 2019 (COVID-19) cases on board the Diamond Princess cruise ship, Yokohama, Japan, 2020. Euro Surveill. 2020;25: https://doi.org/10.2807/15607917.ES.2020.25.10.2000180

10. Roxby AC, Greninger AL, Hatfield KM, Lynch JB, Dellit TH, James A, et al. Detection of SARS-CoV-2 among residents and staff members of an independent and assisted living community for older adults- Seattle, Washington, 2020. MMWR Morb Mortal Wkly Rep. 2020;69:416-8. https://doi.org/10.15585/mmwr.mm6914e2

11. Tian S, Hu N, Lou J, Chen K, Kang X, Xiang Z, et al. Characteristics of COVID-19 infection in Beijing. J Infect. 2020;80:401-6. https://doi.org/10.1016/j.jinf.2020.02.018

12. Ng O-T, Marimuthu K, Chia P-Y, Koh V, Chiew CJ, De Wang L, et al. SARS-CoV-2 infection among travelers returning from Wuhan, China. N Engl J Med. 2020;382:1476-8. https://doi.org/10.1056/NEJMc2003100

13. Li C, Ji F, Wang L, Wang L, Hao J, Dai M, et al. Asymptomatic and human-to-human transmission of SARS-CoV-2 in a 2-family cluster, Xuzhou, China. Emerg Infect Dis. 2020. https://doi.org/10.3201/eid2607.200718

14. Tong ZD, Tang A, Li KF, Li P, Wang HL, Yi JP, et al. Potential presymptomatic transmission of SARS-CoV-2, Zhejiang Province, China, 2020. Emerg Infect Dis. 2020;26:1052-4 https://doi.org/10.3201/eid2605.200198

15. Yu P, Zhu J, Zhang Z, Han Y, Huang L. A familial cluster of infection associated with the 2019 novel coronavirus indicating potential person-to-person transmission during the incubation period. J Infect Dis. 2020. https://doi.org/10.1093/infdis/jiaa077

16. Ye F, Xu S, Rong Z, Xu R, Liu X, Deng P, et al. Delivery of infection from asymptomatic carriers of COVID-19 in a familial cluster. Int J Infect Dis. 2020;94:133-8; https://doi.org/10.1016/j.ijid.2020.03.042

17. Bai Y, Yao L, Wei T, Tian F, Jin DY, Chen L, et al. Presumed asymptomatic carrier transmission of COVID-19. JAMA. 2020; 323:1406. https://doi.org/10.1001/jama.2020.2565

18. Hu Z, Song C, Xu C, Jin G, Chen Y, Xu X, et al. Clinical characteristics of 24 asymptomatic infections with COVID-19 screened among close contacts in Nanjing, China. Sci China Life Sci. 2020;63:706-11. https://doi.org/10.1007/s11427-020-1661-4

19. Zhang J, Tian S, Lou J, Chen Y. Familial cluster of COVID-19 infection from an asymptomatic. Crit Care. 2020; $24: 119$. https://doi.org/10.1186/s13054-020-2817-7

20. Pan X, Chen D, Xia Y, Wu X, Li T, Ou X, et al. Asymptomatic cases in a family cluster with SARS-CoV-2 infection. Lancet Infect Dis. 2020; 20: 410-1. https://doi.org/10.1016/S1473-3099(20)30114-6

21. Rothe C, Schunk M, Sothmann P, Bretzel G, Froeschl G, Wallrauch C, et al. Transmission of 2019-nCoV infection from an asymptomatic contact in Germany. N Engl J Med. 2020; 382:970-1. https://doi.org/10.1056/NEJMc2001468

22. Furukawa NW, Brooks JT, Sobel J. Evidence Supporting Transmission of Severe Acute Respiratory Syndrome Coronavirus 2 While Presymptomatic or Asymptomatic. Emerg Infect Dis 2020; 26(7): https://doi.org/10.3201/eid2607.201595

23. Temkin E et al. Extremely low prevalence of asymptomatic COVID-19 among healthcare workers caring for COVID-19 patients in Israeli hospitals: a cross-sectional study. Clinic Microbiol Infec. 2020; https://doi.org/10.1016/j.cmi.2020.09.040

24. Al-Sadeqa DW, Nasrallaha GK. The incidence of the novel coronavirus SARS-CoV-2 among asymptomatic patients: A systematic review. Int J Infect Dis 2020; (98): https://doi.org/10.1016/j.ijid.2020.06.098

25. Gallagher, J., 2021. New Coronavirus Variant: What Do We Know?. [online] BBC News. Available at: <https://www.bbc.com/news/health$55388846>$ [Accessed on January 3, 2021].

26. Hassoun, N., 2021. How To Distribute A COVID-19 Vaccine Ethically. [online] Scientific American. Available at: <https://www.scientificamerican.com/article/how-to-distribute-a-covid-19-vaccine-ethically/> [Accessed on January 3, 2021].

27. Zhang R, Yixin Y, Zhang AL, Wang Y, Molina MJ. Identifying airborne transmission as the dominant route for the spread of COVID-19.

\section{Tables}

Page 8/11 
Table 1. Detail of pre-symptomatic and asymptomatic transmission of COVID-19 in contacts within 24 hour prior to appearance of symptoms or confirmation of infection

\begin{tabular}{|c|c|c|c|c|c|c|c|}
\hline & $\begin{array}{l}\text { Total } \\
\text { contacts }\end{array}$ & $\begin{array}{l}\text { Average } \\
\text { contacts }\end{array}$ & $\begin{array}{l}\text { Min- } \\
\text { Max }\end{array}$ & $\begin{array}{l}\text { Infection } \\
\text { Transmitted }\end{array}$ & $\begin{array}{l}\text { Infection } \\
\text { Not } \\
\text { Transmitted }\end{array}$ & $\begin{array}{l}\text { Mean Days } \\
\text { from } \\
\text { Confirmation }\end{array}$ & Min-Max \\
\hline Total $(n=201)$ & 7168 & 35.66 & $4-87$ & $64(0.89 \%)$ & 7104 (99.11\%) & $84.0 \pm 43.0$ & $23-200$ \\
\hline $\begin{array}{l}\text { Pre- } \\
\text { symptomatic } \\
(n=155)\end{array}$ & 5611 & 36.20 & $4-87$ & $63(1.12 \%)$ & $5548(98.88 \%)$ & $85.32 \pm 43.5$ & $24-210$ \\
\hline $\begin{array}{l}\text { Asymptomatic } \\
(n=46)\end{array}$ & 1557 & 33.85 & $6-84$ & $1(0.06 \%)$ & $1556(99.94 \%)$ & $82.74 \pm 42.5$ & $23-180$ \\
\hline
\end{tabular}

Table 2. Detail of transmission traced by pre-symptomatic and asymptomatic COVID-19 patients in AJK

\begin{tabular}{|c|c|c|c|c|c|}
\hline Patient type & $\begin{array}{l}\text { Time duration before symptoms or } \\
\text { confirmation }\end{array}$ & $\begin{array}{l}\text { Total } \\
\text { Meetings }\end{array}$ & $\begin{array}{l}\text { Average } \\
\text { Meetings }\end{array}$ & $\begin{array}{l}\text { Infections } \\
\text { Transmitted }\end{array}$ & $\begin{array}{l}\text { Transmissior } \\
\text { Percentage }\end{array}$ \\
\hline \multirow{6}{*}{$\begin{array}{l}\text { Pre-symptomatic } \\
(n=155)\end{array}$} & Total (0-24 hours) & 5611 & 36.20 & 63 & $1.12 \%$ \\
\hline & $0-6$ hours & 1544 & 9.96 & 62 & $4.01 \%$ \\
\hline & 6-12 hours & 1410 & 9.09 & 1 & $0.07 \%$ \\
\hline & $12-18$ hours & 1285 & 8.29 & 0 & $0.00 \%$ \\
\hline & $18-24$ hours & 1372 & 8.85 & 0 & $0.00 \%$ \\
\hline & Total 6-24 hours & 4067 & - & 1 & $0.02 \%$ \\
\hline \multirow{5}{*}{$\begin{array}{l}\text { Asymptomatic } \\
(n=46)\end{array}$} & Total (0-24 hours) & 1557 & 33.85 & 1 & $0.0 .06 \%$ \\
\hline & $0-6$ hours & 353 & 7.67 & 0 & $0.00 \%$ \\
\hline & 6-12 hours & 436 & 9.48 & 1 & $0.23 \%$ \\
\hline & $12-18$ hours & 478 & 10.39 & 0 & $0.00 \%$ \\
\hline & 18-24 hours & 290 & 6.30 & 0 & $0.0 \%$ \\
\hline
\end{tabular}

Table 3. Detail of 8 selected case reports out of the total 201 cases in the study 


\begin{tabular}{|c|c|c|c|c|c|c|c|c|c|c|}
\hline $\begin{array}{l}\text { Case } \\
\text { No }\end{array}$ & Area & Category & Gender & Age & $\begin{array}{l}\text { Date of } \\
\text { symptoms } \\
\text { or } \\
\text { Confirmation }\end{array}$ & $\begin{array}{l}\text { Contacts } \\
\text { in last } \\
24 \\
\text { hours }\end{array}$ & Tested & $\begin{array}{l}\text { Found } \\
\text { Positive }\end{array}$ & $\begin{array}{l}\text { Developed } \\
\text { Symptoms } \\
\text { on day } 14\end{array}$ & $\begin{array}{l}\text { Transmission } \\
\text { Percentage }\end{array}$ \\
\hline 1 & Palandari & Symptomatic & Male & 50 & $\begin{array}{l}\text { May 30, } \\
2020\end{array}$ & 42 & 25 & 0 & 0 & $0 \%$ \\
\hline 2 & Rawalakot & Symptomatic & Male & 21 & $\begin{array}{l}\text { Aug 01, } \\
2020\end{array}$ & 32 & 21 & 0 & 0 & $0 \%$ \\
\hline 3 & Rawalakot & Symptomatic & Male & 66 & Jul 08, 2020 & 56 & 28 & 1 & 1 & $1.8 \%$ \\
\hline 4 & Hajira & Symptomatic & Female & 47 & Jun 16, 2020 & 27 & 11 & 3 & 3 & $11.1 \%$ \\
\hline 5 & Rawalakot & Asymptomatic & Male & 29 & $\begin{array}{l}\text { May 22, } \\
2020\end{array}$ & 54 & 13 & 0 & 0 & $0 \%$ \\
\hline 6 & Rawalakot & Asymptomatic & Female & 27 & Jun 02, 2020 & 37 & 13 & 0 & 0 & $0 \%$ \\
\hline 7 & Rawalakot & Asymptomatic & Male & 50 & Sep 12, 2020 & 26 & 8 & 0 & 0 & $0 \%$ \\
\hline 8 & Rawalakot & Asymptomatic & Male & 39 & Jul 14, 2020 & 23 & 9 & 1 & 0 & $4.3 \%$ \\
\hline
\end{tabular}

\section{Figures}

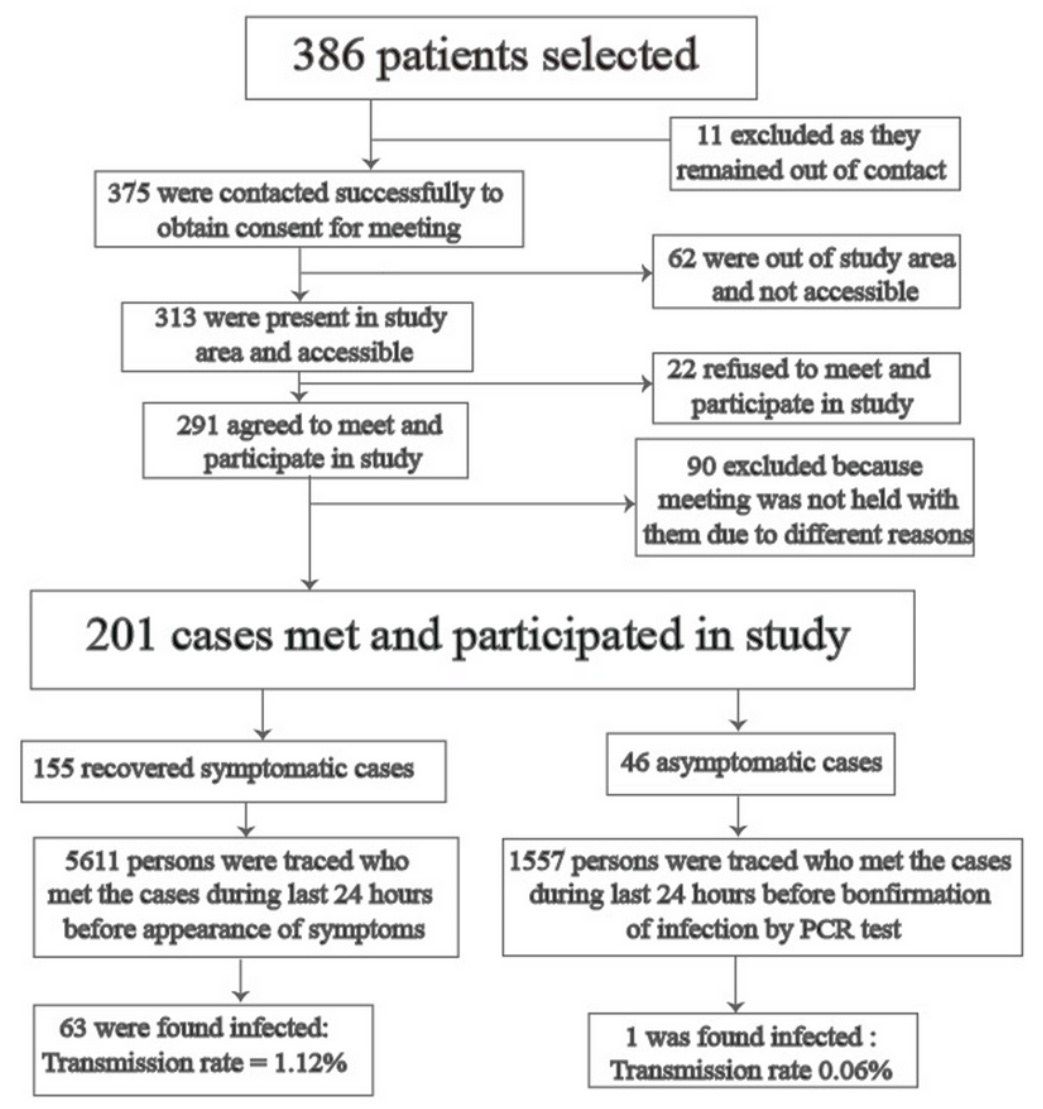


Figure 1

The flow chart of study methodology with inclusion and exclusion of study participants 